tượng gây ra bạo lực là bệnh nhân là chủ yếu 72,1\%; người nhà người bệnh chiếm tỷ lệ cao 62,6\%; đồng nghiệp 14,3\%. Nguyên nhân chính gây lên bạo lực gồm: Do người bệnh đợi chờ lâu 85,6\%, Tăng stress ở người bệnh/người nhà người bệnh 84,4\%; Lạm dụng rượu, ma túy ở nnb và người nhà người bệnh 74,1\%. Hậu quả tâm lý ở điều dưỡng viên phổ biến gồm: Stress $85,7 \%$, tức giận 83,7\%, thất vọng 79,6\%, mất sự tự trọng $74,2 \%$, sợ hãi $72,1 \%$. Hậu quả thể chất có ở 34,7\% điều dưỡng viên, phải nghỉ làm chiếm 2,0\%. Cânn có chế tài hành vi gây rối, hành hung nhân viên y tế. Nâng cao nhận thức cộng đồng trong việc phòng ngửa bạo lực nơi làm việc cho điều dưỡng viên tại bệnh viện.

\section{TÀI LIỆU THAM KHẢO}

1. US Department of Justice. Workplace violence: issuse in reponse. Federal Bureau of Investigation; 2013.

2. Nancy A Perrin, Helen Moss. Workplace violence against homecare workers and its relationship with workers health outcomes: a cross-sectional study. BMC Public Health. 15(1):11.

3. Dương Tấn Quân. Thực trạng bao lực bệnh viện với điểu dưỡng và một số yếu tố ảnh hưởng tai bệnh viện Bà Rịa năm 2019. Tạp chí Y học dự phòng. 2019;29(8):71.

4. Đố Mạnh Hùng, Đào Ngọc Phúc, Phạm Thu Hiên. Mô tả một số nguyên nhân, hậu quả bạo lực nơi làm việc ở điều dưỡng viên do khách hàng gẩy ra tại các khoa lâm sàng Bệnh viện Nhi Trung ương, năm 2017. Tap chí $Y$ học thành phổ Hồ Chí Minh. 2018;2(6):201-7.

5. Sisawo EJ, Ouédraogo SYYA, Huang S-L, Workplace violence against nurses in the Gambia: mixed methods design. BMC Health Services Research [Internet]. 2017 Apr 28 [cited 2021 Aug 29];17(1):311. Available from: https://doi.org/10.1186/s12913-017-2258-4

6. Abed $M$, Morris $E$, Sobers-Grannum $N$. Workplace violence against medical staff in healthcare facilities in Barbados. Occup Med (Lond). 2016 Oct;66(7):580-3.

7. Basfr W, Hamdan A, Al-Habib S. Workplace Violence Against Nurses in Psychiatric Hospital Settings: Perspectives from Saudi Arabia. Sultan Qaboos Univ Med J. 2019 Feb;19(1):e19-25.

\title{
CHẨN ĐOÁN VÀ XỬ TRÍ MộT TRƯờNG HỢP RÒ DƯỡNG CHẤP SAU PHẪU THUẬ̂T U NANG VÙNG CỔ TRÁI
}

\section{TÓM TẮT}

Một bệnh nhân với khối u vùng cổ trái lớn nhập viện 15/11/ 2017. Sau phẫu thuật cắt bỏ u, có hiện tượng rò dưỡng chấp xảy ra. Số lượng dưỡng chấp lền đến $1000 \mathrm{ml} / \mathrm{ngày}$. Việc phát hiện sớm và phải can thiệp phẫu thuật sớm thắt lại ống ngực cho kết quả tốt. Đây là trường hợp hiếm gặp. Qua trường hợp này, nhằm đề cập đên lậm sàng, phát hiện rò dưỡng chấp trong quá trình phẫu thuật và các phương pháp điều trị nhằm giúp các nhà lâm sàng có hướng xử trí khi gặp.

Từ khóa: rò dưỡng chấp, ống ngực.

\section{SUMMARY}

DIAGNOSIS AND TREATMENT OF A CHYLOUS FISTULA AFTER LEFT NECK MASS SURGERY

The patient man has a left neck mass and come to hospital on November, $15^{\text {th }}, 2017$. After removing total mass of left neck, he had chylous fistula. The volume of chile secreted about $1000 \mathrm{ml} /$ days. He had diagnosised a serious chylous leakage after neck

*Bệnh viện Chợ Rẫy

Chịu trách nhiệm chính: Ngô Văn Công

Email: congtmh@gmail.com

Ngày nhận bài: 18.6.2021

Ngày phản biện khoa học: 16.8.2021

Ngày duyệt bài: 23.8.2021
Ngô Văn Công*

surgery. This case is rarely happen in medical practice. We indentified a chylous fistula early and to cure to prevent serious complication. After operating to suture thoracic duct fistula, he was stable health. This case shows clinical symptoms and diagnosis a chylous fistula to help physican can indentify same case in the future.

Keywords: chylous fistula, thoracic duct fistula.

\section{GIỚI THIÊUU}

Rò dưỡng chấp thì rất dễ nhận ra nhưng là biến chứng hiếm gặp trong phẫu thuật đầu cổ, chiếm khoảng $1-2,5 \%$ trong phẫu thuật nạo vét hạch cổ [1],[2]. Điều trị rò dưỡng chấp khó khăn và kéo dài, thậm chí có thể đe dọa tính mạng. Giải phẫu của ống ngực thay đổi và đặc điểm dễ rách do đó dễ bị tổn thương trong quá trình phẫu thuật. Từ đó gây mất lượng lớn protein và dịch giàu chất điện giải có thể gây ra xáo trộn chuyển hóa và gây khó khăn trong quá trình lành thương tại chổ và toàn thân.

Chúng tôi báo cáo một trường hợp xử trí thành công một trường hợp rò dưỡng chấp sau phẫu thuật nang vùng cổ trái nhằm mục đích để các Bác sĩ chuyên khoa nhận biết và định hướng chẩn đoán và xử trí trong quá trình thực hành lâm sàng. 


\section{BÁO CÁO CA LÂM SÀNG}

Bệnh nhân nam 52 tuổi, vào viện vì khối sưng vùng cổ + thượng đòn trái. Với bệnh sử: khoảng 3 tháng trước, bệnh nhân phát hiện có 1 khối u nhỏ ở vùng cổ trái U không đau, không nóng, không đỏ, không sốt. Bệnh nhân đi khám tại bệnh viện Chợ Rẫy với chẩn đoán Đa nhân 2 thuỳ tuyến giáp và được chỉ đinh phẫu thuật cắt toàn bộ tuyến giáp, sau phẩu thuật u không giảm mà ngày càng to dân $\rightarrow$ Nhập viện BV Chợ Rẫy 15/11/ 2017.

Lâm sàng: Khối u ở vùng cổ trái, tròn, căng, không đỏ, không đau, di động dưới da. Chẩn đoán xác định là u nang cổ trái.
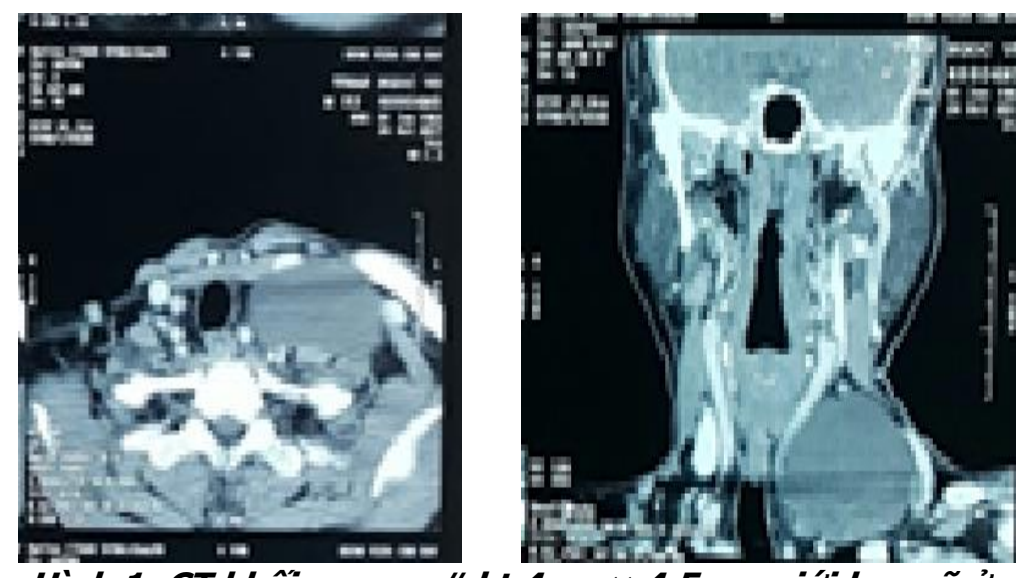

Hình 1: CT khôii u nang \# kt 4cm $\times$ 4,5cm, giới hạn rõ ở vùng hốm ức - thượng đòn trái, ép bó mach cảnh

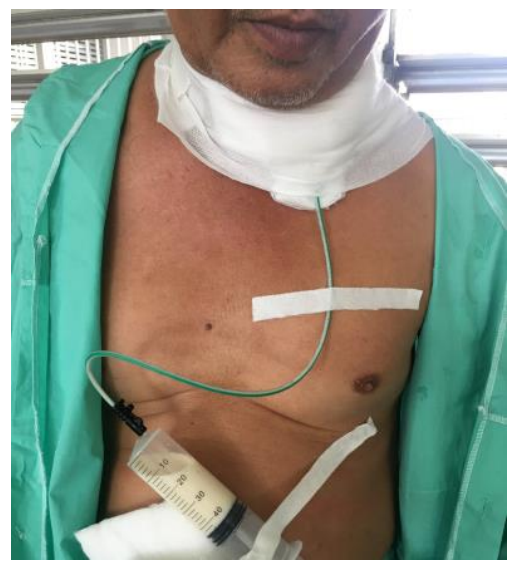

Hình 2: dưỡng châp thoát ra dân Iưu
Bệnh nhận được tiến hành phẫu thuật, gây mê toàn thân. Bóc tách cơ ức đòn chũm ra ngoài, cắt cơ vai móng bên trái, vén bó mạch cảnh vào trong. U to bám vào nền cổ đi xuống đến mặt sau xương đòn trái, bóc tách lấy u, thấy dính vào vùng bạch mạch phía sau, cột vùng dính vào nền cổ. Cầm máu, đặt ống dẫn lưu áp lực âm. Hậu phẫu ngày 1, tình trạng vết mổ khô, dẫn lưu ra dịch màu hồng nhạt khoảng 100ml. Đến hậu phấu ngày thứ 2 cổ hơi sưng nề, vết mổ khồ nhưng dẫn lưu ra dịch màu trắng đục khoảng $750 \mathrm{ml} /$ ngày. Và hậu phẫu ngày thứ 3 cổ sưng nhiều hơn, vết mổ khô, dẫn lưu ra dịch màu trắng đục khoảng $1000 \mathrm{ml}$ nhiêu hơn các ngày trước (hình 2), tăng nhiều sau khi ăn. Đước chẩn đoán xác định là rò dưỡng chấp sau phẩu thuật nang cổ trái.

Bêenh nhân được chỉ định phẫu thuật thám sát lại vết mổ. Rạch da theo đường mổ cũ, mở rộng xuống hõm ức. Thấy hố mổ cũ chứa đây dịch trắng đục nghĩ dịch bạch huyết, hút sạch. Thấy vùng ống ngực $T$ vùng nền cổ dã cột còn thấm dịch trắng đục, mổ trắng bờ chảy lan tỏa từ mạng bạch huyết xung quanh cạnh vùng thực quản. Tiến hành khâu cột vùng ống ngực T bằng chỉ Prolene 4.0. Nhét hố mổ bằng Surgicel lưới và keo sinh học. Đặt dẫn lưu 2 ống. Cầm máu kĩ, khâu da 2 lớp, băng ép. Sau phẫu thuật lại, tình trạng bệnh nhân ổn sau 1 tuần và được xuất viện.

\section{BÀN LUẬN}

3.1. Chẩn đoán: Thường các tổn thương ống ngực bị che khuất hoặc khó nhận ra trong lúc phẩu thuật. Khi xảy ra tổn thương ống ngực và có thể không rõ ràng cho đến vài ngày sau phẫu thuật. Giải phẫu ống ngực có thể thay đổi vì khối u làm thay đổi vị trí trí giải phẫu bình thường. Vì vậy cần thận trọng trong phẫu thuật thì rất cần thiết. Nếu nạo vét hạch cổ trước đó khó khăn hoặc rò dưỡng chấp được xác định trong quá trình phẫu thuật thì việc thắt ống ngực sẽ thành công và kiểm soát tốt hơn.

Về lâm sàng rò dưỡng chấp sau phẫu thuật biểu hiện không rõ ràng. Vết thương sau mổ thường sưng lên không rõ nguyên nhân. Bên cạnh đó, tăng dịch dẫn lưu hoặc dịch dẫn lưu tăng đột ngột sau khi ăn [1]. Xuất hiện dịch trắng đục, sệt và váng mõ trong dẫn lưu thì nghi ngờ cao là dưỡng chấp.

Cận lâm sàng: thường xét nghiệm dưỡng chấp có sự xuất hiện triglyceride và tỷ lệ triglyceride tăng. Nồng đồ triglyceide trong dịch dẫn lưu > 100 mg/dl hoặc tỷ lệ triglyceride cao hơn trong huyết thanh thì giúp chẩn đoán dịch đó là do rò dưỡng chấp [7].

3.2. Điêuu trị: Theo y văn có 2 loại rò dưỡng chấp, rò nhiêu cao và rò ít. Rò nhiều là khi dưỡng chấp > 500 ml/ ngày đến 1000 ml. ngày $[1],[4],[5]$. Hâu hết các tác giả đều đồng thuận 
rò dưỡng chấp nhiều thì thất bại với điều trị bảo tồn [5]. Rò ít thì ít gặp và có thể điều trị bảo tồn. Khi xác định rò dưỡng chấp, điều trị bảo tồn nên thực hiện ngay với nghĩ ngơi tại gường và bắt đầu nuối ăn qua sond dạ dày với chế độ ăn ít triglyceride [3]. Cần theo theo dõi liên tục dấu hiệu sinh tồn, cân bằng dịch, xét nghiệm điện giải và chức năng gan.

Điêuu trị bảo tồn rò dưỡng chấp. Nghĩ ngơii tại chổ thì quan trọng, vì khi hoạt động nhiều sẽ làm tăng bài tiết dưỡng chấp. Và dẫn lưu được đặt tại nền của vết mổ trong cuộc phẫu thuật cho phép theo dõi rò dưỡng chấp và cũng theo dõi dẫn lưu dịch dẫn lưu. Băng ép tại chổ không khuyến nghị vì không hiệu quả mà có thể gây cản trở máu nuôi đến vạt da [2],[3].

Cần xác định lượng dịch xuất nhập hàng ngày, cùng với điện giải. Và xét nghiệm chức năng gan bao gồm albumin và chức nằng thận nhằm giúp hướng dẫn bổ sung chế độ ăn và điều trị cho bệnh nhân [5]. Chế độ ăn cho bệnh nhân rò dưỡng chấp rất quan trọng. Lượng dịch và điện giải mất phải được thay thế, tình trạng dinh dưỡng của bệnh nhân phải được duy trì. Có thể duy trì chế độ ăn kiên để cố gắng giảm tạo ra dưỡng chấp. Hầu hết các tác giả khuyến nghị một chế độ ăn cơ bản ít triglyceride cho bệnh nhân rò dưỡng chấp. Chế độ ăn ít triglyceride được hấp thu trực tiếp vào hệ tuần hoàn tĩnh mạch mà không vào hệ thống bạch huyết, sẽ giảm bài tiết dưỡng chấp. Do đó, một số tác giả đã báo cáo chế độ dinh dưỡng ít triglyceride đơn thuần có thể hiệu quả ngưng rò dưỡng chấp trong những trường hợp rò dưỡng chấp lượng nhe - trung bình [3].

Khi chế độ dinh dưỡng không hiệu quả, thì có thể nuôi dưỡng bẳng tĩnh mạch [2]. Nuôii dưỡng tĩnh mạch bằng cách bẽ gãy các chuỗi acid béo ở ruột non, và phân phối phospholipid trực tiếp vào tĩnh mạch trung tâm, giảm đáng kể lượng tạo ra dưỡng chấp. Tuy nhiên, đặt tĩnh mạch trung tâm có tỷ lệ biến chứng cao có thể thủng động mạch, tụ máu, thủng phổi và nhiễm trùng muộn. Đặt tĩnh mạch trung tâm, gia tăng nhiễm trùng catheter và xáo trộn chuyển hóa bao gồm tăng đường huyết và mất cân bằng điện giải [10].

Ngoài ra còn có thuốc ức chế tạo ra dưỡng chấp. Somatostatin và các octreotide tổng hợp tác động lên hoạt động bài tiết của dạ dày, tuyến tụy và ruột, và cũng giảm tiết dưỡng chấp [6]. Những thuốc hiệu quả với rò dưỡng chấp mức độ trung bình - nhẹ, thời gian sử dụng khoảng 2 tuần [1].

Điều trị bằng phẫu thuật: Điều trị can thiệp phẫu thuật rò dưỡng chấp có thể chia thành 2 nhóm: nhóm tại chổ để xác định vị trí rò dưỡng chấp hoặc nhóm phẫu thuật tìm đầu xa thân của dòng dưỡng chấp trong ống ngực.

Nhóm can thiệp tại chổ là mở lai vết thương và xác định vị trí chảy dưỡng chấp. Chú ý vị trí này thường bị viêm bởi dưỡng chấp và có thể ẩn phía bên dưới là các cấu trúc mạch máu và thần kinh quan trọng [2],[3] vì vậy, khi mở lại vết thương cũng dễ bị tổn thương các cấu trúc này. Đế xác định được vị trí rò, một số tác giả đề nghị ăn chế độ mõ trước phẫu thuật [8]. Nếu rò nhỏ và vị trí rò tốt, thám sát có thể được hiện bằng gây tê tại chố [1]. Phẫu thuật lại bao gồm thắt, khâu vị trí rỏ nhìn thấy với chỉ không tan hoặc clip phẫu thuật [2],[3]. Trong trường hợp rò trong báo cáo chúng tôi, khi mở ra mô viêm xung quanh vết thương, lãy sạch mô viêm cẩn thận, thì dịch trong xuất tiết vùng ống ngực bị tổn thương và lan tỏa. Chúng tôi đã thắt nhiều vị trí và kiểm tra kỹ vùng vết thương, mũi thắt khâu hình chữ $X$ bằng chỉ không tan, đặt surgicel vá dán bằng keo sinh học. Đã mang lại kết quả tốt. Bên cạnh đó, một số tác giả khuyến cáo dùng vạt tại chổ: vạt cơ ngực lớn hoặc đầu ức của cơ ức đòn chũm lắp vào che phủ. Và làm dính lại bằng chất keo sinh học. Phủ lên phẫu trường Vicryl mesh [4],[9]. Một số tác giả khác cũng đề nghị trong trường hợp xác định rò dưỡng chấp trong lúc phẫu thuật thì sau đó nên khâu vắt với chỉ không tan đặt surgercel và dán keo sinh học tương tự các khuyên cáo [1],[3], sau đó đă̆t dẫn lưu để theo dõi. Băng ép không khuyến cáo đặc biệt có vạt vi phẫu do làm thiếu máu nuôi cho vạt [3].

Phẫu thuật đầu xa: phẫu thuật lại tìm vị trí rò có thể khó khăn trong một số trường hợp do cấu trúc giải phẫu thay đổi, nguy cơ tổn thương các cấu trúc quan trọng và có thể thất bại khi can thiệp rò dưỡng chấp lượng nhiều hoặc những trường hợp khó. Stuart đã tổng kết vào đầu những năm 1900 thắt ống ngực ở bệnh nhân sắp tử vong [9]. Nhiều kỹ thuật đã được phát triển từ đó để ngăn rò dướng chấp trong ống ngực ở đầu xa như tạo ra ông thông xuyên qua bụng của ống ngực, thắt ống ngực qua nội soi ngực... Nễu dẩn lưu dưỡng chất quá $1000 \mathrm{ml} /$ ngày khônng đáp ứng với điêu trị bảo tồn, nên sắp xễp phẫu thuật thắt ống ngực qua nội soi ngực.

\section{KẾT LUẬN}

Rò dương chấp sau phẫu thuật cùng cổ thì hiếm nhưng có khả năng gây biển chứng trầm trọng. Việc xác định sớm rò dưỡng chấp sau 
phẫu thuật rất quan trọng và xác định rò dưỡng chấp lượng nhiều hay ít, giúp phẫu thuật viên có hướng giải quyết sớm. Rò dưỡng chấp sau phẫu thuật có thể điều trị bảo tồn. Khi điều trị bảo tồn thất bại có thể can thiệp ngoại khoa thắt ống ngực.

\section{TÀl LIẸU THAM KHẢO}

1. Crumley R. L., Smith J. D. (1976) Postoperative chylous fistula prevention and management. Laryngoscope, 86 (6), 804-13.

2. de Gier H. H., Balm A. J., Bruning P. F., Gregor R. T., Hilgers F. J. (1996), Systematic approach to the treatment of chylous leakage after neck dissection. Head Neck, 18 (4), 347-51.

3. Lucente F. E., Diktaban T., Lawson W., Biller H. F. (1981), Chyle fistula management. Otolaryngol Head Neck Surg, 89 (4), 575-8.

4. Muthusami John C., Raj John P., Gladwin D. Gaikwad Pranay, Sylvester Shalom (2005), Persistent chyle leak following radical neck dissection: a solution that can be the solution. Annals of the Royal College of Surgeons of England, 87 (5), 379-379.
5. Nussenbaum B., Liu J. H., Sinard R. J. (2000), Systematic management of chyle fistula: the Southwestern experience and review of the literature. Otolaryngol Head Neck Surg, 122 (1), 31-8.

6. Rimensberger P. C., Müller-Schenker B., Kalangos A., Beghetti M. (1998), Treatment of a persistent postoperative chylothorax with somatostatin. Ann Thorac Surg, 66 (1), 253-4.

7. Rodgers G. K., Johnson J. T., Petruzzelli G. J., Warty V. S., Wagner R. L. (1992), Lipid and volume analysis of neck drainage in patients undergoing neck dissection. Am J Otolaryngol, 13 (5), 306-9.

8. Spiro J. D., Spiro R. H., Strong E. W. (1990), The management of chyle fistula. Laryngoscope, 100 (7), 771-4.

9. Stuart 'W. J. (1907), Operative Injuries of the Thoracic Duct in the Neck. Edinburgh Medical Journal, 22 (4), 301-317.

10. Knochel James P. (1985), Complications of total parenteral nutrition. Kidney International, 27 (3), 489-496.

\section{BƯớC ĐẦU MÔ TẢ NỒNG Độ KHÁNG THỂ KHÁNG VI RÚT SARS-COV-2 SAU TIÊM VẮC XIN PHÒNG COVID-19}

\section{TÓM TẮT}

Nghiên cứu đã tiến hành quan sát nồng độ kháng thể kháng vi rút SARS - CoV - 2 trên 80 đối tượing, bao gồm 9 đối tượng chưa tiêm vắc xin, 20 đối tượng đã được tiêm 1 mũi và 51 đối tương tiêm 2 mũi với hai mục tiêu 1) Mô tả đặc điểm đối tượng sử dụng xét nghiệm đinh lượng kháng thể sau khi tiêm vắc xin phòng ngừa Covid-19 2) Mô tả kết quả xét nghiệm định lượng nồng độ kháng thể kháng vi rút SARS CoV - 2 sau khi tiềm vắc xin phòng ngừa Covid-19. Kết luận: Các tác dụng không mong muốn phổ biến được ghi nhận sau khi tiêm vắc xin 1 mũi và mũi 2 là sốt, ớn lạnh, đau đâu, đau mỏi người và đau sưng tại vị trí tiêm. Tỷ lệ xuất hiện tác dụng không mong muốn ở cả 2 nhóm là tương đương. Kết quả định lượng kháng thể kháng vi rút SARS - CoV - 2 của mâuu nghiên cứu cho thây $100 \%$ các nhóm đã tiêm vắc xin đều có đáp ứng miên dịch với SARS - CoV - 2 ngay tù̀ mũi 1 và cao hơn so với nhóm chưa tiêm ít nhất 12 lần (nhóm tiêm 1 mũi) cho đến 71 lần (nhóm sau tiêm 2 mũi 2 tuần). Tiêm đủ 2 mũi vắc xin giúp cơ thể của các đối tương nghiên cứu đat được nồng độ kháng thể cao hơn rõ̃ rệt so với khi tiềm 1 mũi. Nồng độ kháng

\footnotetext{
${ }^{1}$ Bệnh viện Đa Khoa Quốc Tế Hải Phòng

2 Trường Đai hoc Y Dước Hải Phòng

Chịu trách nhiệm chính: Nguyễn Thanh Hồi

Email: hoinguyenthanhbm@gmail.com

Ngày nhận bài: 18.6.2021

Ngày phản biên khoa hoc: 11.8.2021

Ngày duyệt bài: 23.8.2021
}

Nguyễn Thanh Hồi ${ }^{1,2}$, Nguyễn Thị Thu Phương ${ }^{1,2}$

thể kháng vi rút SARS-Covid-2 vào tuân thứ 3 sau tiêm mũi 2 thấp hơn so với nhóm sau tiêm mũi 22 tuần. Từ kết quả phân tích trên, chúng ta thây rằng tiêm vắc xin phòng Covid-19 giúp sản sinh kháng thể chống lại vi rút SARS-CoV-2. Tuy nhiên, lượng kháng thể này khác nhau giữa các đối tượng và thay đổi theo thời gian sau khi tiêm phòng.

Tư khóa: Kháng thể kháng SARS - CoV - 2, vắc xin Covid-19

\section{SUMMARY \\ INITIAL DESCRIPTION OF ANTIBODY LEVELS AGAINST SARS - COV - 2 VIRUS AFTER VACCINATION AGAINST COVID-19}

The study observed the concentration of antibodies against SARS - CoV - 2 virus on 80 subjects, including 9 subjects who had not been vaccinated, 20 subjects received 1 dose of vaccine and 51 subjects received 2 doses with two objectives 1 ) Characterization of subjects using quantitative antibody testing after vaccination against Covid-19 2) Description of test results to quantify antibody levels against SARS - CoV - 2 after being vaccinated against Covid-19. Conclusion: Common adverse effects reported after vaccination with 1 dose and 2 doses were fever, chills, headache, body aches and pain and swelling at the injection site. The percentage of subjects with pain and swelling at the injection site accounted for the highest rate in both groups, this rate accounted for $60 \%$ in the group after $1^{\text {st }}$ injection and $74,5 \%$ in the group after $2^{\text {nd }}$ dose of vaccin. We recorded the rate of occurrence of human fatigue 